\title{
A Heuristic Model of Supervision Using Small Objects to Develop the Senses
}

\author{
Drew Bird* \\ Senior Lecturer Therapeutic Arts, University of Derby, UK
}

*Corresponding author: Drew Bird, Senior Lecturer Therapeutic Arts, College of Health and Social Care, University of Derby, UK.
Received Date: June 03, 2019

Published Date: July 31, 2019

\section{Introduction}

For a Drama therapy supervisor, it's important to have a suitable model for supervision practice; a model that guides, supports, empowers and enables the supervisee to discover emerging themes in their development as a therapist. The model needs to be flexible enough to utilize non-verbal means of communication and at the same time help to focus the supervisee's experience as a therapist. Such a model would be suitable to explore the tensions between personal experience and professional roles, as unworked-through themes in one's personal life will emerge in one's professional practice [1]. The supervision model needs to be flexible enough to contain chaos and uncertainty, but not too rigid or restrictive to limit creativity. The purpose of this paper is to consider a research model suitable for supervision that is suited and congruent to eliciting the supervisee's senses through the use of small symbolic objects. The purpose of supervision is to help the supervisee work with personal or professional limitations that might impact on the client work and support their exploration to enable them to go beyond the familiar self.

\section{What is Drama Therapy?}

Drama therapy is a unique psychotherapy that intentionally uses both the nature of theatre and drama for healing, change and transformation [2]. Clients/patients are actively facilitated to project aspects of themselves onto roles, characters, stories, puppets, images and objects, to name a few of the many ways Drama therapists might work. By actively projecting aspects of themselves onto a fictionalized story or drama clients/patients externalize their internal state, whereby the dynamics of their invisible world are made visible $[3,4]$. The visible dramatic metaphor thus separates the patient/client sufficiently from the problematic material and helps create distance from everyday reality that makes exploration and expression safe [4,5]. Playing with the dramatic material thus enables the client/patient to hide and conceal themselves, but paradoxically to reveal $[3,6]$. The dramatic metaphor offers aesthetic distance and illusion to "maintain the safety of the me/ not me experience of safety". The safety is reinforced through offering the client/patient the choice to recognize the self (or not) as revealed through the art form [5].

The development of a character in a story that is distanced from everyday reality offers the potential to develop new ways of engaging the body and moving in a new way. On a smaller scale one can explore movement and the senses through puppetry, props or small object work to explore one's experience. Drama therapy uses the site of the body and the senses for further exploration that can help generate new possibilities that are not previously available through "literal representation" and everyday consciousness. Drama therapy engages the body and the senses unlike more verbal psychotherapies [7]. The exploration of the body offers opportunity to go beyond the usual everyday thoughts as cognitions and habits that can limit and imprison one [8].

\section{Drama Therapy Supervision}

Supervision is about being able to receive support, step back and reflect on one's experience as a therapist and 'engage in the search for new options' [9]. In order for supervision to be effective and to maximize the learning and professional development opportunity, a trusting relationship between supervisor and supervisee is essential so they can reflect safely [10]. Helping the supervisee be open, receptive and non-defensive in their exploration is a central theme in supervision practice [11], enabling the supervisee to explore freely and be at their best so they can maintain standards, be effective and offer assurances that the client is receiving a quality service [12]. In the UK the British Association of Drama therapists (BADth) consider the aims of Drama therapy supervision 
as supporting the supervisee's professional development, critical reflection, efficacy of practice and exploration of "the relationship between the client and the therapist and the impact of this on the therapy" [13].

Drama therapy supervision is not unique in recognizing the need for support, trust and a space to reflect on practice so the supervisee can be effective as a therapist. The relationship dynamics of supervision form a triangular relationship involving the client, therapist and supervisor; however, in drama therapy a fourth component is used which is that of the art form, which can be used to substitute any of the three roles to metaphorically explore client material and relationship dynamics [14]. Drama therapy supervision, like Drama therapy, utilizes dramatic metaphor and symbolism as central to the supervision process. Drama therapy supervisors use many different approaches such as theatrebased models [15,16], Role models [17], Action techniques [18], psychodynamics models [19] and models that use small objects $[20,21]$. This is not an exhaustive list and there are many other approaches that might reflect supervisors' interests and professional background. It is thus important to recognize that there is no one Drama therapy supervision approach that is definitive, yet there might be some agreement in the field that there is a commitment to utilizing "creativity, exploration and imagination" as central to the supervision process [12].

Drama therapy supervisors do not exclusively work with Dramatherapists or arts therapists but might use their artsbased approaches to supervision with other therapists and counsellors of different orientations [15]. The model of supervision proposed is informed by supervising Dramatherapists, trainee Dramatherapists, psychotherapists and counsellors and in this respect could be adapted by a supervisor of any orientation. The use of art-based models in supervision does not require the supervisee to be artistic, more a willingness to explore possibilities, 'learning to tolerate ambiguity' and develop conceptualization skills of the therapeutic work using symbol and metaphor to consider clinical understanding [22]. The use of natural objects such as shells and pebbles can enable those who may be resistant to the use of art or who regard themselves as non-creative to find a way to explore, express and find meaning in a less-threatening way [23]. The model offered thus helps to minimize the supervisee's inhibitions, but as with all models they need to be used sensitively and with due consideration of the supervisee's uniqueness.

\section{The Link Between Research and Supervision}

The intention of this paper is to consider a model of supervision using small objects within a suitable research frame [24]. Explore the increase in research and supervision practice and best practices in supervision [9]. Recognize that supervision is a form of research on practice - the intention to discover more effective ways of practicing as a therapist. Supervision could be considered a form of action research. [25] suggest action research is a form of "selfreflective enquiry" with emphasis on change and learning, rather than problem solving. The focus of action research is research on oneself in the company of others [26]. The others, sometimes known as co-researchers, help to explore practice in the context of a relationship dynamic to aid practitioner reflexivity. The supervision process mirrors action research in that the supervisee is reflecting on their practice in the company of the supervisor to explore and develop as a therapist.

\section{A Supervision Model}

The development of the model is informed by my background as a Drama therapy supervisor that utilizes a unique approach to psychotherapy using the dramatic arts, where "articulating the layers of thinking, understanding, conceptualizing, and applying is the task of the supervisor" [27]. Linking theory and practice in supervision is a complex process within the practice of therapy. For this reason, a suitable supervision model needs to help contain the complexities, layers and multiple possibilities for developing the supervisee's understanding. Discovery is inherently important to supervision as it helps to expand the supervisee's understanding and perspective by increasing awareness about one's practice as a therapist so one can be more effective. In this paper I intend to explore the seven characteristics of heuristic inquiry as discovered by Moustakas (1990) and illustrate how a research frame is suited to developing the supervisee's ability to be creative using symbolic representation. Heuristic inquiry is deemed a suitable methodology as it encourages the use of the arts and the imagination, by drawing on the intuition in order to deepen one's understanding [28]. The underpinning of heuristic inquiry is based on the Greek word 'heuriskein', meaning to discover or find, and uses the self as data to understand oneself more fully [28]. [29] [Etherington] argues that heuristic inquiry can be used for personal growth and professional development as we learn about ourselves when carrying out research, and that every encounter we have with clients is a kind of 're-search'.

\section{Researcher Reflexivity and Heuristic Inquiry}

Researcher reflexivity explores the researcher's values, bias and resulting tensions impact on qualitative research; one thus makes transparent perceptions and interpretations through the filters of subjective experience and demonstrates awareness of being aware [30]. Research is thus an inter-subjective relationship as "the self in relation to others becomes both the aim and the object of focus" [30]. Whilst researchers may no longer debate the importance of reflexivity as part of the research process, reflexivity is now considered research itself as in autoethnography and heuristic research approaches [30]. Reflexivity is looking at the inter-subjective relationship between researcher and research; researcher and participant. Supervision is reflecting on the 'supervisees' therapeutic work with their clients' and furthering one's understanding of the intersubjectivity of the client/therapist dynamic through transference and counter-transference [9]. Both the supervisor and the supervisee need to develop the ability to reflect and cultivate a "critical gaze" [30] to question how their personal and professional experiences may impact on the research, therapeutic work and the effectiveness of the supervisory 
relationship. The resources of the supervisee and their ability to engage fully in the client's world are central to the therapeutic work. Maintaining a resourceful state requires awareness of one's own narrative and how unworked through histories can be activated through the client work [15]. Heuristic inquiry could be considered a model to inform such self-development and self-awareness and pushes against the limits and boundaries of understanding. The endeavor of supervision is to reflect on all aspects of the supervisee's work that 'include appropriate relationship building, management of personal boundaries, dual relationships, (and) conflicts of interest' [31]. The main characteristics of the heuristic methodology as outlined are identifying with the focus of the inquiry, self-dialogue, tacit knowing, intuition, indwelling, focusing and the internal frame of reference [28]. I will consider the heuristic methodology and how its characteristics support the supervision model using of small objects. The objects act as metaphors drawing out the intuitive and creative resources of the supervisee to further understanding of the client work.

\section{Identifying with the Focus of the Inquiry}

Heuristic inquiry focusses on "open-minded inquiry" in order to understand oneself and the experiences of others more fully $[28,32]$.

\section{Becoming a more aware supervisee}

To be dedicated to helping the client requires a commitment from the supervisee to immerse themselves in supervision and self-reflection. The supervisee discovers factors that might impede a successful therapeutic outcome for the client. It is by the questioning of oneself as a supervisee through self- reflection that they discover personal tendencies, patterns and rigid thinking or "emotional blind spots" that can impede the therapeutic process [33]. The supervisee's task, much like [8] and his approach to actor training, is to discover the obstacles or "conditioned blockages" that might impede one from being more spontaneous and more present [34]. By being present the therapist is able to respond with ease and flexibility to the emerging needs of the client.

\section{Developing critical reflection}

Questioning one's practice through critical reflection with a supervisor helps to retain openness to the possibilities of the therapeutic work. In this way the supervisee is able to consider different perspectives of the client work, steer away from rigidity and move towards an open attitude. The shift here is towards a playful attitude, much like 'play' in Jones' core processes of Drama therapy that permit a flexible exploration of different possibilities towards events and ideas [3].

Initially the supervisee is presented with a range of natural and found objects, such as pebbles and shells. They are encouraged to explore the objects and be open to their emerging curiosity. The intention for the supervisee is to find an object that symbolically represents the client. It may be that the supervisee has already made clear what they wish to explore from their caseload, or by exploring the objects they intuitively decide on a focus. The supervisee is actively encouraged to not only look at the objects but feel and smell them. In this respect the intuitive and playful element is enabled, whereby the supervisee considers how the different objects represent the client metaphorically. Metaphors in themselves are playful because they are open to an array of interpretation and possibility and thus not fixed. The supervisee might consider a range of objects to represent the client before they settle on one object for more in-depth exploration. As a supervisor my role is to manage and facilitate the supervisee's conceptualization and different interpretations of the client work [35]. It's important that the supervisee identifies strongly with the object and that the metaphorical link with the client speaks to them, rather than forcing a connection. By developing the use of their senses their intuitive response is fostered so the supervisee can explore their immediate experience of the object.

Whilst the supervisee is exploring the sensory experience of a chosen object with their hands it's important to enable them to be open to new encounters and facilitate a flexible attitude towards their experience. Staying with the not knowing of the playful state and allowing meanings to emerge suspends certainty and its associations with reductive thinking [36]. As I observe the supervisee, I feed back to them the kind of movements I observe as they develop a sensory relationship with the object. It's important at this stage that observations are as clean and free of supervisor's interpretation as possible, such as, 'I notice you are moving your thumb in a circular motion'. In this way the supervisee is free to interpret the movement in their own way that builds safety, but also helps them develop confidence and a sense of responsibility. For example, they might consider circular movements as nurturing or soothing and link this to a maternal instinct and role they tend towards within the therapeutic relationship. The supervisor's unique way of seeing things and observations helps contribute to the supervisee finding their own perspective on the client work [37]. By using somatic and sensory experience the supervisee is able to penetrate their bodily experience to reveal and uncover hidden truths that may lie outside of the supervisee's immediate experience. In this way depths of the supervisee's experience can be uncovered so they can be present within the therapeutic work.

\section{Self-Dialogue}

Heuristic inquiry develops autonomous skills in self-dialogue to "encounter and examine" experience, enabling one to be "open and receptive to all aspects of one's experience" [28].

\section{Non-verbal dialogue}

How might this examination of the supervisee's experiencelook? The use of the senses in supervision has the potential to help the supervisee to explore and examine the fullness of their experience by developing sensory play. Sensory play and embodiment explore the range of sensations directly encountered by the body such as touch, smell, sight and sound [38]. The use of an object helps to develop these senses and externalise the supervisee's inner experience [3]. The object has the quality of 'otherness' in that 
it is over 'there' and separate from me and thus helps to develop dialogue [4]. Self- dialogue need not be verbal but can utilize the senses. In this way the supervisee develops a sensory dialogue with the object, exploring their responses to the object non-verbally. As the supervisee explores the chosen object with their hands, they 'charge up' the object with the client's presence, much as masks carry a charge [39]. The charging up of the object has the potential to elicit aspects of the therapeutic relationship.

The supervisee is encouraged to articulate the different sensations of their experience, whether the object feels rough or smooth, cool or warm. The focus on the object, rather than on the supervisor, may help the supervisee relax and talk with more ease and in this respect a free association is encouraged. Sometimes a supervisee can feel hesitant exploring the object that represents a client. The intimacy of touch can go counter to the reality of a therapeutic relationship where touch is not generally encouraged. The supervisee may be avoidant touching aspects of the object and consider they may be evading areas of the client's life. However, staying with the somatic experience of the object may help to uncover more of the supervisee's unease about aspects of the object. Exploration using touch can facilitate dormant experiences, as touch and somatic experience can elicit the unconscious. As I observe the supervisee, I'm curious about the manner in which they touch the object, observing their non- verbal communication through their hands. The supervisee is encouraged to describe and explore their sensory experience and suspend the temptation to rationalize their experience so they can remain with the directness of their encounter with the object. As soon as the supervisee attempts to explain their experience through interpretations their natural expression can be distorted [40]. It is by staying with their untainted experience of the object they are able to access more of their unconscious experience that may be played out in the therapeutic dynamic. [15] Argues that employing the senses in supervision helps the supervisee reveal and show more directly the dynamics of their practice rather than being over-reliant on verbal communication. Sometimes "Perhaps words are not enough to convey a message in supervision" [31] and other creative means are required to access experiences that are less conscious.

\section{Broadening awareness through the senses}

The shell helps to provoke new experiences through the senses that are beyond reason and cognition. The use of creativity in supervision can help to access the 'pre-verbal and sub-verbal intelligence...which have not been accessible to our reasoning self' [41]. The object helps the supervisee engage non-verbally and access aspects of their knowing they may have been unaware of [20]. Thus, metaphor has the potential to reveal unconscious motivations that may not be congruent with the supervisee's conscious intent [42]. explored how developing the senses through a symbolic object helped the supervisee become aware of thoughts and feelings they had pushed away. They were able to be more congruent with uncomfortable experiences and be more aware of their own attachment patterns and the impact this could have on their practice as a counsellor.

\section{Tacit Knowing}

The tacit dimension in heuristic inquiry recognizes that one knows more than one is aware of or can express verbally [43]. Tacit knowledge gives "birth to the hunches and vague, formless insights" that characterize heuristic inquiry [44].

\section{Exploring impulses}

Supervision is an opportunity to give space for exploration so that insights into the supervisee's practice can arise. By developing the sense experience of the supervisee through an object, the vague experiences are made more real through the concreteness of the object and become more tangible for exploration [4]. The object is used as the means to transform hunches into possibilities that may link to unprocessed and unconscious experiences in the supervisee [42]. Explore how a supervisee explored their relationship with the client, exploring a dried gnarled object that made a rattling sound, helping them reflect that the client was a tough nut to crack and understand. The supervisee is encouraged to explore the object with their hands and follow their impulses. Following one's impulses is important if one is gone "beyond the known, the expected, or merely possible" [44]. The use of the object helps draw on the supervisee's intuitive and spontaneous self to find new meaning [45]. Earlier education has taught us not to take risks for fear of failure and to suppress one's impulses [39]. It is important to recognize that developing hunches is not always congruent with one's conditioning. There are often fears associated with developing impulses, especially within the supervisory relationship when potential power- dynamics may impact on the trust needed to explore freely and respond to one's impulses. Encouraging the supervisee to follow their instincts through small hand movements helps to draw out more of their non-verbal experience that has the potential for new insights. As a supervisor observing a supervisee explore an object with their hands it's important to follow the nonverbal cues, rather than being over-reliant on verbal cues. The supervisee's verbal interpretation may not always be congruent with what they are expressing with their hands. When exploring an object, the supervisee may express being uncomfortable with how an object feels, yet their hands continue to move over the object. The incongruence in their experience can become a clue for deepening their exploration by following the energy of their non-verbal communication through their hands. Repeated hand-movements can give birth to hidden fascinations with the object that may come as a surprise to the supervisee. Repeated movements can create a sense of comfort and help to relax the mind, thus enable the supervisee to be more open to their sensory experience by suspending thought. Staying with any emerging movement patterns helps to build a relationship with the object and develop 'feelings' for it that can offer clues about the potential unconscious therapeutic dynamic with the client. The non-verbal communication of the supervisee thus helps to access difficult to reach themes that words alone may not be able to convey.

\section{Working with uncertainty}

The development of their sensory experience helps the supervisee to realize the hidden aspects of their experience and 
to inquire after it. By following the instincts, one is opening up to uncertainty, letting go of what one knows and moving away from certainty and rigidity that can be characterized by the thinking mind [46]. [47] [Solnit R] argues that it is important to locate oneself in a different terrain where one is beset with uncertainty; the unknown and self-doubt are pre-requisite for discovery. The chosen object represents one such terrain that offers a new landscape for exploration that can alleviate habits beset with exploration in the more familiar context of verbal communication.

\section{Intuition}

[29] [Etherington $\mathrm{K}$ ] argues that heuristic inquiry that utilizes the sense experience of the body helps with tacit knowing and moves one beyond cognitive processing.

\section{Discovering patterns through the non-verbal experience}

The senses and the non-verbal can be gateways to exploring "patterns" as they have the potential to "shed some light" on the supervisee's experience in another way [28,48]. Peter Brook considers how the body hints at "codes and impulses that are hidden" and revealed through listening and observing the body. By drawing on the senses as expressed in the body the supervisee explores intuitive clues that are creative rather than relying on the well- used cognitive processes that are prone to repeating old patterns [46]. Cognitive processes may be more predictable and familiar; however, over- reliance on cognition may offer limited opportunity for exploring the hidden clues in one's experience. It is the supervisor's responsibility to facilitate and broaden the supervisee's awareness and understanding [49]. [42] [] Explore how a supervisee used the metaphor of smell and how they associated the client with a sweaty and musty smell. As a consequence, the supervisee was drawn to the smell outside in the open air that was fresh, clean and hopeful. They were able to reflect that they wanted to avoid some experiences because they did not feel brave enough to confront them. By developing the supervisee's responses to smell the supervisee was able to explore potentially dormant aspects of their experience that verbal approaches alone may have struggled to reach.

\section{Re-conceptualizing the therapeutic dynamic using metaphor}

By choosing an object to metaphorically represent the client the supervisee is able to re-conceptualize the client and the therapeutic work by giving it a different form to warrant exploration in a new way. Re-conceptualizations of the client work helps with the creation of a new narrative. Supervision helps to identify patterns in the supervisee's thinking that might offer clues to rigid thinking about the client which can stultify the development of new possibilities. Narrative therapy recognizes how dominant and rigid stories can limit one's growth and development. It's important to develop new narratives so the supervisee can adopt a flexible approach and be opened to re-authoring their understanding of the client $[3,50]$. Emerging patterns and themes are always pointing beyond themselves. They help to go beyond the known in order to discover the unknown.

\section{Indwelling}

This is characterized by "turning" inward to seek a deeper and fuller understanding of human experience [28].

\section{Being- with the client/patient}

Focusing on the inner world of the supervisee is important within the current therapy culture with more focus on outcome. Therapists, whilst resources for helping others, are also people who need to be resourced, and turning inward to listen to themselves is important if the supervisee is going to remain effective. [51] [Paramananda] explores different relationship dynamics between self and others such as "being-with" as indwelling. The way the supervisee explores the object with their hands helps to intensify the 'being with' and focuses the supervisee's attention so they can go "beyond the appearance of things, beyond the presented thoughts and feelings" [51]. However, it is the staying with the 'being with' and remaining with the sensory exploration of the object through indwelling that enables the supervisee to deepen their experience and go beyond their first presentation and interpretation.

Once the supervisee has explored their sensory associations with the object, they are invited to locate the client object on a piece of paper of about A4 in size. The positioning of the object on the paper can be of further interest, whether this be in the middle of the paper or towards the edges, it communicates non-verbally the supervisee's perception of the client. Just the act of letting go of the object can offer clues for further exploration and whether they do this carefully or clumsily or even with reluctance. The letting go of the object could suggest the way a session with a client may close and hint at wider themes for the supervisee's and client's generic relationship with endings. The non-verbal action helps with the turning inward as it may not be a conscious action and thus helps the supervisee have a more complete understanding of a dynamic in the therapeutic relationship. It is important that the supervisor offers clear and considered observation of the location of the object as the non-verbal communication offers an array of possible interpretations for the supervisee that can deepen their understanding of themselves. The role of the supervisor is to ask questions to help the supervisee with their exploration and taking responsibility for their own interpretation of their experience [35].

Inviting the supervisee to consider another object to represent themselves as therapist helps to develop awareness of the therapeutic dynamic. The supervisee locates the object representing the therapist on the paper in relation to the object representing the client. The proximity of the objects and their differences and similarities in size, color and texture are observed and reflected upon. Dynamics in the therapeutic relationship that may have been hinted at are now more visual and consequently more revealing. The visual element helps to make visible what may have been invisible in the therapeutic dynamic. The visual nature of the objects also helps the supervisee to be more distanced and objective, acting as witness to their creation. The new perceptual position helps new meanings to emerge that may not have been so apparent when they were more subjectively engaged. Different perceptual positions 
can be developed by encouraging the supervisee to view the object dynamic by moving and locating themselves into a different position relative to the image on the paper. This could be left or right of the image, or standing up, or from another position in the room. Taking up different physical positions helps to alleviate familiar or fixed views of the client-therapist dynamic that can open up new insights for consideration.

\section{Focusing}

[44] Douglass BG, et al. suggest that focusing helps one to go beyond everyday distractions that may inhibit one's focus, identifying experiences that are beyond normal consciousness. It is this 'staying with' one's immediate attention and contacting the "core central meanings of an experience" that characterize focusing [28]. Focusing resonates with concepts of sustained attention as in meditation, where one is trying to "re-inhabit" the body by developing more of a relationship with the physical sensations of the body [52]. By developing more awareness of the physical self, one is able to distance oneself from one's thinking and thus see more clearly tendencies and habitual patterns of thinking. By focusing on direct experience generated through the senses, the supervisee is able to experience themselves in a new way where they are less preoccupied with distracting thoughts and more aware of their direct sensory experience [53].

\section{Focusing on the otherness of the symbolic object}

The more the supervisee is able to elicit the details of the otherness in the object the more distance they are able to create from their everyday experience [4]. The focusing on the otherness of the object also helps to alleviate self-consciousness that can be a block to exploration. The focus on the otherness resonates with the work of acting coach, Sanford Meisner, who devised actor training that focused actors intently on the otherness of fellow actors to alleviate self-consciousness. Meisner argued that this approach helped actors be more present, spontaneous and receptive to others [54]. Focusing the supervisee on the specific details of the object helps the supervisee engage more deeply with their present experience, much like the actor pays attention to detailing of a character that helps make it more real and bring it to life [54,55].The process of supervision is about bringing the supervisee's experience into the present moment. By focusing and detailing the object distance is created that helps to create safety, but paradoxically one comes closer to one's experience [56]. The utilization of small objects helps create aesthetic distance from the therapeutic work, creating a meta perspective so the supervisee and supervisor can make a "direct observation" of the therapeutic process through the imagery used in supervision [57].

Encouraging the supervisee to describe the sensations they experience and elicit their own language and metaphors offers gateways into the supervisee's personal experience that offer clues as to where personal material and professional practice may collide. In this way the possible transferences, counter-transferences and the unaware therapist's reaction to the client's material are helped to reveal themselves [9]. Lewis [58] argues an approach to transference and counter transference by being open to exploring the therapist's bodily somatic and sense experience to develop awareness of the client and therapist dynamic.

\section{The Internal Frame of Reference}

The internal frame of reference in heuristic inquiry encourages one to look at one's own experience through "perceptions, thoughts, feelings, and sense" as these are "portrayals" of experience [28].

\section{The supervisee's relationship patterns}

It is by understanding one's feelings, thoughts, body, senses and the imagination that one becomes aware of one's inner story so one can be attentive and available to the stories of clients [59]. Being more aware of one's own story enables one to connect with others. It can be helpful after a period of observing and witnessing the image of the objects to return to exploring their sensory nature again by picking either of the objects up. What can be of interest here is how the sensory experience might have changed for the supervisee; perhaps earlier the object might have felt rougher, but by re-visiting the object it might feel smoother. In this way the supervisee's internal frame of reference can change by moving between the different sensory orientations of touch and visual imagery. Revisiting the symbolic client-therapist dynamic by employing touch can help to deepen the supervisee's experience and go beyond their initial experience and draw out more fully feelings and perceptions. The supervisee may experience the object representing the therapist as lighter or Heavier, which can help them consider what might have happened in their experience of the object to have changed. If the supervisee experiences the therapist object differently, then this could impact on the way they perceive client object or vice versa. In this manner there is a systemic consideration of how a change in one part of the system impacts on the relationship dynamic. As perceptions change about the different symbolic objects it may warrant that the arrangement of the objects needs changing. The supervisee may want to move the objects closer together or further apart and thus consider and re-consider different possibilities in the therapeutic alliance. By encouraging the supervisee to experiment in this way they start to play with their frame of reference and adopt a playful stance in their thinking. The intention here is to help the supervisee pay more attention to their internal references and develop confidence attuning to their somatic experience so there is better balance between the body and the mind.

The supervisee's sensory relationship with the object has the potential to replicate the supervisee's attachment patterns earlier childhood relationship dynamics with primary caregivers can get played out in the therapeutic dynamic. Somatic experiences that relate to earlier attachment patterns are thus activated through the sensory play with the object "our senses are the most important aspect of our early embodied experience" [60]. The object itself isn't of prime importance here, more how the supervisee interacts with the object. Oida \& Marshall [61] argue that in theatre the prop itself is not important but the actor's relationship with the prop needs which needs to be explored and demonstrated. In a similar way the 
supervisee's relationship with the symbolic object is developed in supervision to show, heighten and intensify their experience so they can see more clearly the nature of their relationship within the therapeutic alliance. It is important that their somatic experiences are considered verbally to aid meaning making and interpretation that helps with the body/mind integration. It is important that the supervisee is given opportunity to interpret their metaphors and create new meaning. By trusting their own experience, the supervisee learns to activate tacit knowledge and come to fuller understanding of themselves as a therapist. To know oneself is to become a better therapist. Utilizing supervisee centred approaches nurtures the supervisee's own abilities and activates their own internal supervisor that is both empowering and supportive of their own discoveries [62]. "Gradually supervisees will develop and integrate their own internal supervisor, which will incorporate their own independent thinking, spontaneity, autonomous judgment and result in their creation of their own internal map of the psychotherapeutic process" [63].

\section{Conclusion}

Throughout this paper I have introduced how Drama therapy approaches to supervision might be utilized using a research methodology as a frame for reflective practice. Heuristic inquiry was deemed a suitable methodology to explore sensory and somatic experiences of the supervisee with its emphasis on tacit knowledge, intuition and development of non-verbal clues for deepening the experience of the supervisee.

The use of the senses helps the supervisee pay attention to aspects of their experience that may go unattended or unnoticed due to a propensity to favour more cognitive approaches in reflection. Using objects to elicit the senses is about addressing the potential body/mind imbalance to help the supervisee be aware of more non-verbal cues in relation to the therapeutic dynamics. The characteristics offer a frame for personal and professional development that can be interpreted and owned by the supervisee in their own unique way. A supervision model that utilizes the senses can help the supervisee to explore potential transferences and counter-transferences within the therapeutic dynamic. The supervisee's body holds somatic, sensory and unconscious experiences that can reveal and present themselves through the creative arts [57]. The use of small objects lends itself to helping the supervisee explore the therapeutic relationship dynamics in a new context using symbolism and metaphor [21]. By using sensory play, the supervisee is able to "expand horizons through an imaginary framework" and go beyond the known [16]. Helping the supervisee explore unfamiliar and alternative stories about the therapeutic work guards against rigidity and limited thinking. Supervision is about enabling the supervisee to explore the therapeutic work from a different position and perspective, so they can develop the confidence to create a new hypothesis of the therapeutic work. In this way supervision is about interpreting the many possibilities of metaphor, substituting one possible meaning for another, just as the "artist plays and speculates" [16]. By guiding the supervisee to explore their experiences more fully they become aware and more congruent personally and professionally so there is more alignment between personal values and professional values as a therapist.

\section{Acknowledgement}

None.

\section{Conflict of Interest}

No conflict of interest.

\section{References}

1. Yalom I (2003) The gift of therapy: An open letter to a new generation of therapists and their patients: Reflections on being a therapist London: Piatkus.

2. Health and Care Profession Council (2019).

3. Jones P (2007) Drama as Therapy: Theory, practice and research. London: Routledge.

4. Author (2010) Blinded for Review.

5. Cattanach A (1999) Links between the arts therapies. In A. Cattanach (Edt.), Process in the Arts Therapies pp: 191-197. London: Jessica Kingsley Publishers Ltd.

6. Pitches J (2003) Vsevolod Meyerhold. London and New York: Routledge.

7. Milioni D (2007) Embodiment and metaphor in Dramatherapy: A discursive approach to the extra-discursive. Dramatherapy: 29(3): 3-8.

8. Grotowski J (2002) The actor's technique: an interview with Jerzy Grotowki by Denis Bablet. In E. Barba (Edt.). Towards a poor theatre: Jerzy Grotowski pp: 205-224. New York: Routledge.

9. Hawkins P, Shohe R (2006) Supervision in the helping professions. ( $3^{\text {rd }}$ edn) Open University Press: Berkshire, England.

10. Mc Naughton K, Boyd J, Mc Bride J (2006) Using CORE data in counselling supervision: an initial exploration. European Journal of Psychotherapy and Counselling 8(2): 209-225.

11. Mearns D (1991) On being a supervisor. In W. Dryden and B. Thorne (Eds.), Training and supervision for counselling in action. London: Sage Publication.

12. Jones P (2008a) The state of the art of supervision, In D. Dokter and P. Jones (Eds.), Supervision of Dramatherapy p: 9-32 East Sussex: Routledge.

13. British Association of Dramatherapists (2019) British Association of Dramatherapists: Clinical supervision guidelines for the profession.

14. Couroucli Robertson K (1999) Supervisory triangles and the helicopter ability. In E. Tselikas-Portman (Edt.) Supervision and Dramatherapy. London \& Philadelphia: Jessica Kingsley Publishers.

15. Jennings S (1999) Theatre-based supervision: A supervisory model for multidisciplinary supervisees. In E. Tselikas-Portman (Edt.) Supervision and Dramatherapy. London \& Philadelphia: Jessica Kingsley Publishers.

16. Anderson Warren M, Seymour A (2008) A theatre model of drama therapy supervision. In P Jones, D. Dokter (Eds.), Supervision of Dramatherapy pp: 85-98 East Sussex: Routledge.

17. Landy R (1999) Role model of dramatherapy supervision, In E. TselikasPortman (Ed.), Supervision and Dramatherapy. London \& Philadelphia: Jessica Kingsley Publishers.

18. Jones P (2008b) From role to play: research into action techniques in supervision, In D. Dokter and P. Jones (Eds.), Supervision of Dramatherapy: p: 49-67 East Sussex: Routledge.

19. Jenkyns M (1999) Training the supervisor drama therapist 1: A psychodynamic approach, In E. Tselikas-Portman (Edt.), Supervision and Dramatherapy. London \& Philadelphia: Jessica Kingsley Publishers.

20. Lahad M (2001) Basic ph. model: How to understand the way a supervisee meets the world. In M. Lahad (Ed.), Creative supervision pp: 61-83 London: Jessica Kingsley Press. 
21. Co-Author and Author (2014) Blinded for Review.

22. Deaver SP, Shiflett C (2011) Art based supervision techniques. The Clinical Supervisor 30(2): 257-276.

23. Brooker J (2010) Found objects in art therapy. International Journal of Art Therapy 15(1): 25-35.

24. Borders LD, Glosoff HL, Welfare LE, Hays DG, De Kruyf L, et al. (2014) Best practices in clinical supervision: Evolution of a Counseling Specialty. The Clinical Supervisor 33(1): 26-44.

25. Kemmis S, Mc Taggart R (1988) The action research planner ( $2^{\text {nd }}$ edn) Geelong, Vic: Deaken University Press.

26. Mc Niff J, Whitehead J (2002) Action research: Principles and practice. London: Routledge/Falmer.

27. Holloway E (1995) Clinical supervision. A system approaches. London: Sage.

28. Moustakas C (1990) Heuristic research: Design, methodology, and applications. London: Sage.

29. Etherington $\mathrm{K}$ (2004) Becoming a reflexive researcher using ourselves in research. London: Jessica Kingsley.

30. Finlay L (2003) The reflective journey: Mapping multiple routes. In L. Finlay and B. Gough (Eds.), Reflexivity: A practical guide for researchers for health and social sciences p: 1-3 Oxford. Blackwell Science Limited.

31. Stainsby K (2015) Monitoring the supervisory relationship from the supervisor's perspective, Good Practice in Action 010 Fact Sheet Resource, British Association for Counselling and Psychotherapy.

32. DJ Raskovic I, Arthur N (2010) Heuristic inquiry: A personal journey of acculturation and identity reconstruction. The Qualitative Report 15(6): 1569-1593.

33. Anderson SA, Holmes SE (2007) Personal mythologies: A framework for dealing with therapeutic and supervisory impasses. In S Krippner, M Bova, L Gray (Eds.), Healing stories: The use of narrative in counselling and psychotherapy pp: 125-139. San Juan, Puerto Rico: Puente.

34. Kumiega J (1987) The Theatre of Grotowski. London: Methuen.

35. Scaife J (2001) Supervision in the Mental Health Professions. Hove and New York: Brunner Routledge.

36. Jennings S (1987) Dramatherapy and groups. In S. Jennings (Edt.), Dramatherapy: Theory and Practice 1. London: Routledge.

37. Norberg J, Axelsson H, Barkman N, Hamrin M, Carlsson J (2016) What psychodynamic supervisors say about supervision: Freedom within limits. The Clinical Supervisor 35(2): 268-286.

38. Jennings S (1995) The theatre of healing: metaphor and metaphysics in the healing process. In S. Jennings (Edt.) Dramatherapy with children and adolescents. London: Routledge.

39. Johnstone K (2007) Impro: Improvisation and the theatre. London: Methuen.

40. Lopez Pedraza R (1996) Anselm Kiefer: 'After the Catastrophe'. London: Thames and Hudson.
41. Inskip F, Proctor B (1995) The art, craft and tasks of counselling supervision. Part 2: Becoming a supervisor $\left(2^{\text {nd }}\right.$ edn) Twickenham: Canada.

42. Author and Co-Author (2015) Blinded for Review.

43. Polyanyi M (1983) The tacit dimension. Gloucester MA: Peter Smith.

44. Douglass BG, Moustakas C (1985) Heuristic inquiry: The internal search to know. Journal of Humanistic Psychology 25: 39-55.

45. Wilkins (1995) A creative therapies model for the group supervision of counsellors. British Journal of Guidance and Counselling 23(2): 245-257.

46. Brook P (1998) Threads of time: A memoir. London: Methuen Drama.

47. Solnit R (2005) A field guide to getting lost. Edinburgh: Canongate Books.

48. Tselikas Portman E, Jennings S, Couroucli Robertson K, Kyriacou D (1999) Training the Supervisor-Dramatherapists II: The theatre-based approach. In E. Tselikas-Portman (Edt.), Supervision and Dramatherapy. London and Philadelphia: Jessica Kingsley Publishers.

49. Sommer CA, Ward JE, \& Scofield T (2010) Metaphoric stories in supervision of internship: A qualitative study. Journal of Counselling and Development Fall 88.

50. White M, Epstein (1990) Narrative means to therapeutic end. New York, Norton and Company.

51. Moustakas C (1986) Being in, being for, and being with. The Humanistic Psychologist 14(2): 100-104.

52. Paramananda (1996) Change your mind: a practical guide to Buddhist meditation. Birmingham: Windhorse publications.

53. Beck CJ (1993) Nothing special: Living Zen. New York: Harper One.

54. Meisner S, Longwell D (1987) Sandford Meisner on acting. New York: Vintage Books.

55. Stanislavski C (2013) An actor prepares. London: Bloomsbury Academic.

56. Grainger R, (1999) Challenging safety: Further thoughts about catharsis. Dramatherapy Journal 21(2): 7-9.

57. Calisch A (1995) The Metatherapy of supervision using art with transference/countertransference phenomena. The Clinical Supervisor 12(2): 119-127.

58. Lewis P (1992) The creative arts in transference/counter transference relationships. The Arts in Psychotherapy 19: 317-323.

59. Rennie D (1998) Person centred counselling: An experiential approach. London: Sage.

60. Jennings S (2011) Healthy attachments and neuro-dramatic play. London: Jessica Kingsley Publishers.

61. Oida Y, Marshall L (2007) An actor's tricks. London: Methuen Drama.

62. Rogers C (2003) Client centred therapy: Its current practice, implications and theory. London: Constable.

63. Gilbert M, Evans E (2000) Psychotherapy supervision. 